\title{
Analysis of Performance and Control of DC Microgrids as Electricity Providers for Renewable Energy
}

\author{
Denis $^{1 *}$, Enda Wista Sinuraya ${ }^{1}$, Jaka Windarta ${ }^{2}$, Yosua Alvin Adi Soetrisno ${ }^{1}$ and Kurnianto Fernanda ${ }^{1}$ \\ ${ }^{1}$ Diponegoro University, Department of Electrical Engineering, Semarang, Indonesia \\ ${ }^{2}$ Diponegoro University, School of Postgraduated, Semarang, Indonesia
}

\begin{abstract}
The increase in demand for electrical energy is increasing rapidly, in line with economic growth. In developing the electricity system, electrical energy service providers must provide electrical energy according to demand with good quality. The generation of conventional electric energy systems that use fossil fuels faces depleting fossil fuel sources, poor efficiency, and environmental pollution. This technology is known as Distributed Generation (DG). Distributed Generation (DG) or Micro Grid (MG) is a small-scale power plant located close to the load. The use of distributed generators can improve the entire system's efficiency, reduce transmission losses, reduce pollution, and ensure the continuity of the distribution of electrical energy. However, the drastic increase in the use of DG causes problems in the form of voltage and frequency stability which will be disturbed due to rapid changes in the generation and loading rates. If this is left unchecked, it can harm system security and reliability. A proper control strategy will restore system stability in the event of an imbalance.
\end{abstract}

\section{Introduction}

R.H. Lassete first developed the concept of the micro electric network (Microgrid) in 2002, namely a distributed generation pattern that includes a wide variety of energy sources, ranging from fossil energy to renewable energy sources. The micro electricity network is a network system of interconnection of various energy sources that is channelled into a small network that can operate independently or be connected to the PLN leading network.

The microgrid can be classified into AC microgrid, DC microgrid, and hybrid AC / DC microgrid. DC microgrid is preferred over micro grid AC because of its benefits, namely higher reliability, improved input power quality, reduced losses due to the absence of reactive power, higher efficiency, simple structure, better performance and efficiency of the DC converter. The literature shows that researchers have worked on renewable energy sources, such as hydro, solar, wind, tides, biomass, biogas, and geothermal. Among renewable energy sources, photovoltaic (PV) and Wind Turbine (WG) systems are the primary sources required for energy regulation in the microgrid. This source is also abundant and sustainable The power source from PV and WG is stochastic, and the electricity generated is unstable so it cannot be relied on because the load requires an outputvoltage, that

* Corresponding author: denisginting@elektro.undip.ac.id 
matches the standard load requirements. With the development of semiconductor technology and power electronic converters, the

Power electronic devices dominate future load devices and power generation units. Electronics-based equipment and devices require a DC power source to work, such as computers, fluorescent lamps, Variable Speed Drives (VSD), household, business and industrial appliances. In addition, the available $\mathrm{AC}$ power source is converted into a DC power source to operate this electronic device. Almost $30 \%$ of the AC power source is generated using this electronic converter device, resulting in decreased system efficiency. This problem can be overcome by integrating solar energy sources, wind, and storage systems into DC power. In a DC bus system, the power conversion efficiency increases by $8 \%$ and the savings to about $25 \%$. In addition, setting up a renewable energy-based DC microgrid is more economical than the resource-based generation method of electricity, which reduces the cost of delivering electrical energy and reduces environmental pollution by reducing greenhouse emissions.

\section{Theoretical Background}

\subsection{Electrical Power Distribution System}

The electric power distribution system was divided into three stages: the generation system, the transmission system, and the distribution system. In electric power distribution, the distribution system is an essential part of distributing electrical energy to consumers. The electrical energy generated by conventional generators requires a transmission and distribution system so that the electric power can meet the load requirements. The distribution system is responsible for dividing electricity into several load centres through the substation.

\subsection{Radial Distribution}

The radial distribution system is a distribution system classification based on topology or the arrangement of its series. This radial topology is a topology that is generally used in electric power distribution systems. This is because the topology is the simplest. The radial distribution system is depicted with one PLN utility source drawn forks radially to each load centre. In general, the advantage of the radial distribution system is the simplicity of the circuit arrangement, making it easier to study the power flow and voltage regulation. In addition, in terms of investment costs, radial distribution is relatively cheap. This is due to the use of its few components. The form of the arrangement of the radial distribution circuit can be seen in Figure 1. 


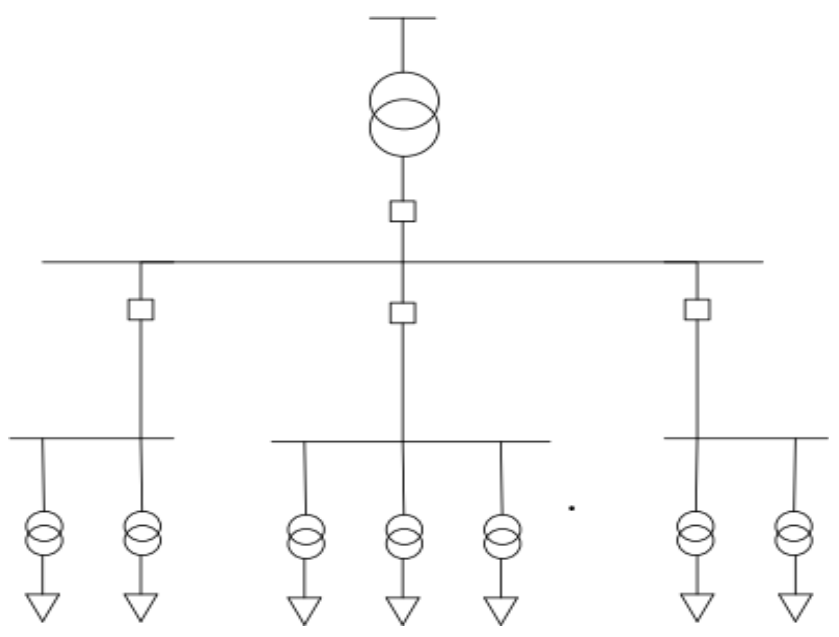

Fig. 1. Radial Distribution System Topology.

\subsection{Microgrid}

A microgrid is defined as part of a distribution network integrated with DG and local loads. The Microgrid is designed to supply electric power to an area with a distribution voltage level. The Microgrid has its generator, namely DG, which is located close to the load centre. The generators used in the Microgrid are generally renewable or non-conventional. Microgrids can operate in mode connected to the leading network (PLN) and mode disconnected from the leading network. These two modes are also called grid-connected and islanding. Here is a typical microgrid configuration:

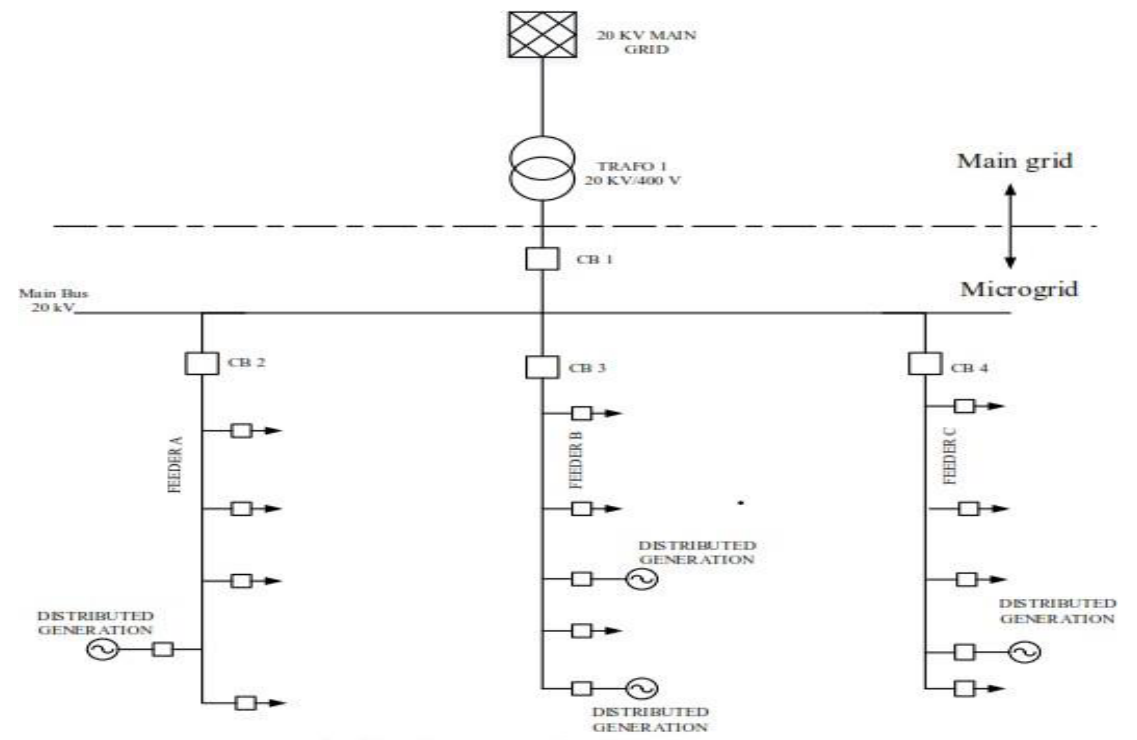

Fig. 2. Microgrid Configuration. 


\subsection{Distributed Generation (DG)}

Distributed generation is a small-scale power generation technology that is located scattered near load centers. Energy sources from DG can be renewable sources (wind, solar heat, water, biomass) or non-renewable sources (diesel, steam, fuel cell). Due to the spread placement ofDG, DG can be integrated with the distribution system to meet load requirements. From several studies, DG can be concluded that it is not centralized and close to the load, small capacity than $50 \mathrm{MW}$ and is connected to the voltage distribution system up to $145 \mathrm{kV}$. The following table shows the classification of DG units based on their capacity.

Table 1. DG Classification Based on Generating Capacity.

\begin{tabular}{|c|c|c|}
\hline Classification & Capacity & Installation \\
\hline Micro & $<2 \mathrm{~kW}$ & Solar Cell \\
\hline Mini & $2 \mathrm{~kW}-10 \mathrm{~kW}$ & Fuel Cell \\
\hline Small & $10 \mathrm{~kW}-1 \mathrm{MW}$ & Biomass, Mini Hydro \\
\hline Medium & $1 \mathrm{MW}-5 \mathrm{MW}$ & $\begin{array}{c}\text { Biomass, Hydro, Wind } \\
\text { Turbine, Diesel }\end{array}$ \\
\hline Large & $>5 \mathrm{MW}$ & $\begin{array}{c}\text { Hydro, Solar Thermal, Wind } \\
\text { Farm, Diesel }\end{array}$ \\
\hline
\end{tabular}

\section{Result and Analysis}

\subsection{Principles Control of DC Microgrids}

Some effective control mechanisms must be devised to guarantee DC Microgrids run effectively and reliably. Figure 1 depicts the overall topology of the Microgrid DC system. Most importantly, DC Microgrids are made up of numerous parallel converters that may operate in various harmonies. This parallel converter local control approach typically consists of the following consecutive components: 1) Photovoltaic (PV) and wind turbine (WT) modules can occasionally function in maximum power tracking (MPPT), and they may also operate to maintain dc bus voltage or current limiting mode. Meanwhile, ESS, which is separate from PV and WT, must be viewed as charge status. 2) Not only is converter control fall control due to its intrinsic modularity and application convenience, but it can also accomplish current coordinates across multiple converters. The converter's resultant drop controlled voltage is shown as an equation.

$V i=V r e f-R v i . I l i$

\subsection{Multilevel Control of DC Microgrids}

Voltage/current regulation, power flow management, and other progressive control functions may be accomplished in the microgrid by adequately running the interface power converter with the advancement and use of electronic energy devices. As we all know, microgrid control and management are multi-functional, including a wide range of technological and physical levels. The importance sphere, which includes the difficulties described above, which are multilevel control methods [12], [13], has been proposed and widely utilized as the standard solution for effective Microgrid management. It is made up of three basic control levels, as seen in Figure 3: 


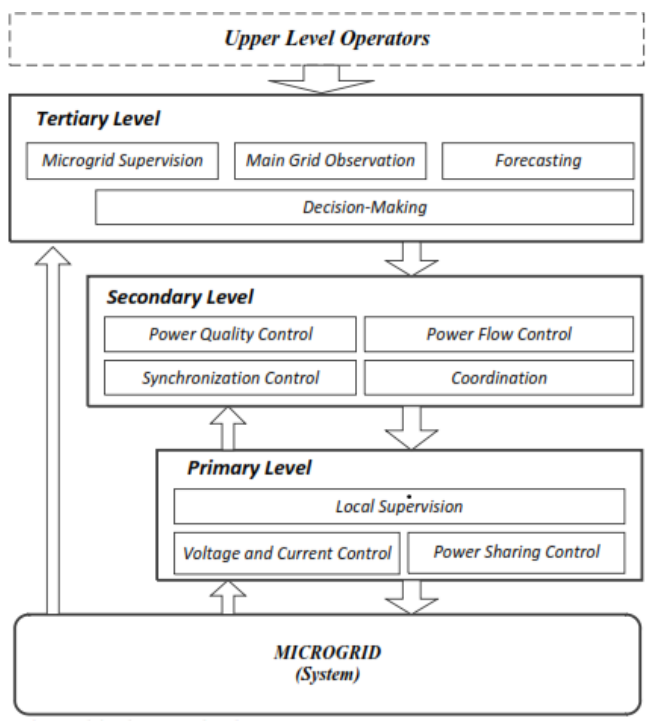

Fig. 3. ControlScheme of Microgrid.

The kind of control level may be divided into three components based on the hierarchy above: the degree of control that can be centralized, decentralized, dispersed, or in a hierarchical form, as illustrated in Figure 4. The structure in Figure 4 can be observed to be based on the specification of control techniques compile. The hierarchical control structure delegated control functions to local and top-level controllers, allowing the system to run more efficiently. The control structure chosen may vary based on the kind of Microgrid.

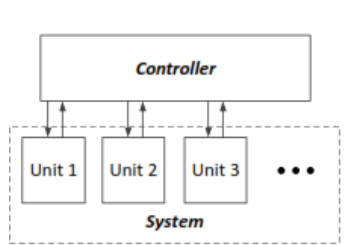

(a)

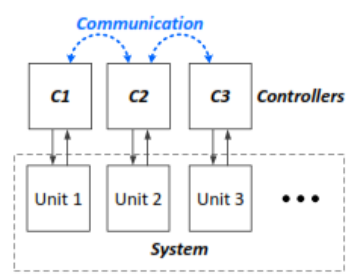

(c)

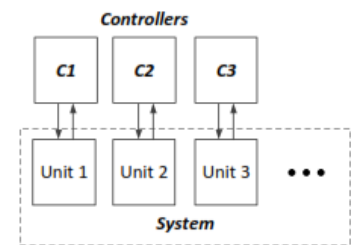

(b)

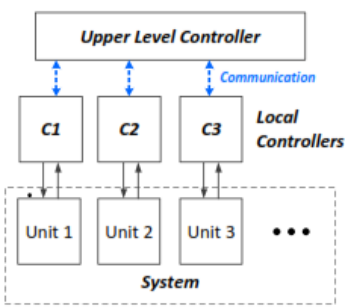

(d)

Fig. 4. (a) centralized; (b) decentralized; (c) distributed; (d) hierarchical

The exact hierarchy is shown in Figure 3, the way DC Microgrid control can be centralized, decentralized, distributed, or hierarchically, as shown in Figure 4. In other words, the structure depicted in Figure 4 is built on a collection of summarized control mechanisms. In a centralized arrangement, the central control unit will gather and transmit data to DG. There is no need for a control center in decentralized and distributed systems. 


\subsection{Decentralized Control}

As previously stated, decentralized coordination is one of the control approaches used in DC Microgrids, the working concept of which is depicted in Figure 5. (a). The decentralized technique may be stated to be capable of coordinating the performance of several parallel converters in DC Microgrids. DBS, PLS and adaptive adjustment techniques are most widely used [14], [15]. This method has several advantages, including simplicity of control and not being affected by digital communication. However, due to the efficacy and dependability of the voltage sensor, they have intrinsic performance restrictions.

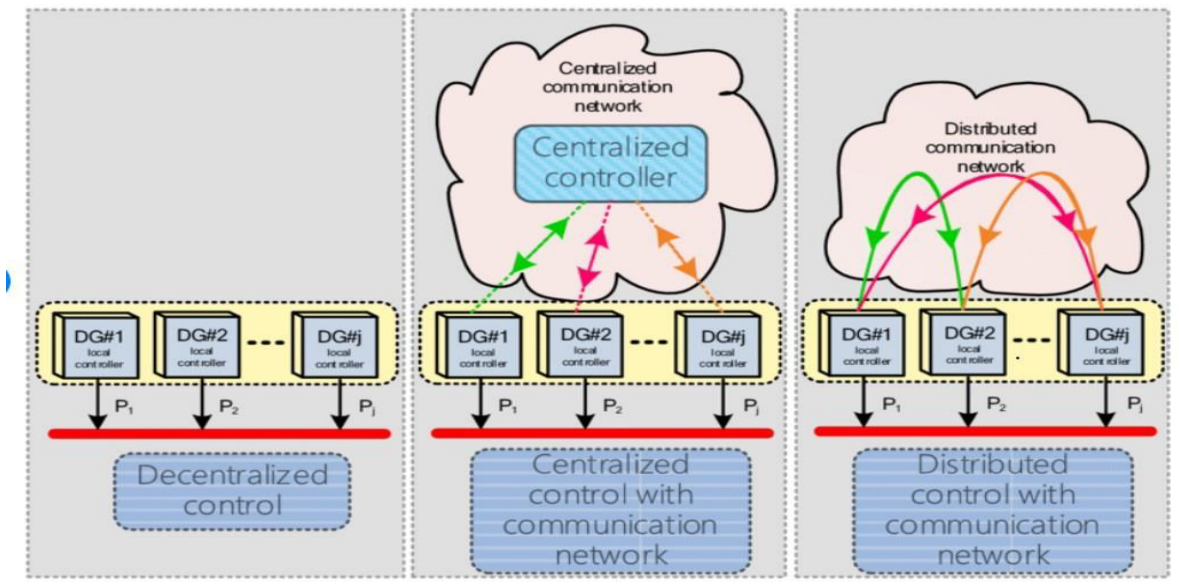

Fig. 5. Operating Principles Control Strategies.

For DC Microgrids, DBS control can be considered the most effective decentralized coordination approach. The operation will be more synchronized between the distribution unit and the DC Microgrids while this method is used. Figure 6 depicts the DBS principle asa fixed state model of a DC microgrid.

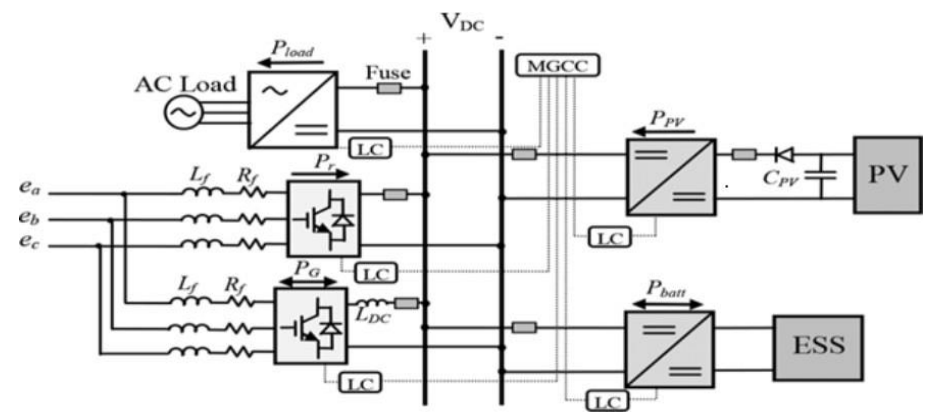

Fig. 6. Fixed model of DC Microgrid.

\subsection{Centralized Control}

Centralized control is a control operation that includes adding a centralized controller to all parallel units, with each parallel unit providing the signal required to assure consistency of the output signal. That is, centralized control may be accomplished in DC Microgrids by using a central controller (CC) and a digital communication network that connects sources 
and loads. In the case of bigger DC Microgrids, hierarchical control is often the better choice because there is a degree of independence between the different levels of control. In addition, as compared to centralized control, hierarchical control is more dependable since its function continues even if centralized control fails. Overall, a single controller can gather and interpret all necessary data, whereas centralized control can provide sophisticated control capabilities.

The use of centralized control is still common today because of its numerous benefits. [16] The predictive control strategy model was created for vehicle dynamics and centred on the vehicle's autonomous driving.

\subsection{Distributed Control}

Distributed control refers to distributed units that are linked together by communication links. The distribution control concept differs from the central control concept. The central control concept does not require a specific digital communication connection and may readily reach the local controller communicating independently, as illustrated in Fig. 5. (c). Even if numerous links break, the system will continue to work normally [17]. As a result, distributed control can effectively handle a single point of failure. Parallel controllers, on the other hand, have a mutual influence on each other. That is, they can degrade the system's transient performance. To minimize the mutual control impact indicated above, [18] proposes a cascade control structure that employs the powersharing control as the inner loop and the bus voltage control as the outer loop.

Overall, it can be argued that distributed control may attain information stability when contrasted to centralized control. As a result, system control objectives such as output current sharing, voltage recovery, overall system efficiency enhancement, ESS SoC balance, and so on may be effectively improved and fulfilled. As a result, distributed control with considerable benefits can provide considerably more extensive functionality than decentralized control. However, distributed control has significant constraints, including the complexity of performance analysis and a non-ideal environment defined by communication time delays and sensor measurement inaccuracies.

\subsection{Power Flow Analysis and Control}

Even though MG systems are often smaller than traditional grids, power flow issues develop when generating and consumer locations are dispersed. The Newton-Raphson technique and its enhanced variants are still commonly used and have proven helpful for pure or DC networks [19] - [21]. The analysis is found in the HVDC system, where the DC network is produced by a voltage source converter, resulting in a multiterminal DC transmission system. The power in the DC system is estimated and managed based on the terminal voltage and the injection of AC side power. Similar approaches, such as virtual impedance/droop control, as shown in Fig. 7, may be used in DC Microgrids systems to increase computation accuracy [22], [23]. 


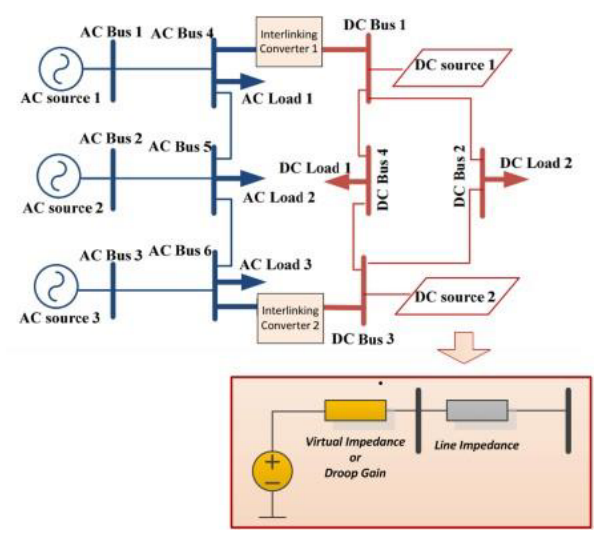

Fig. 7. Power Flow Analysis with virtual impedance/droop gain in DC.

\section{Conclusion}

The Micro-Grid will become increasingly important in the following years, as each system's complexity and impact, particularly the control mechanism, will expand. The control approach in DC Microgrids was evaluated in this research to guarantee that the system functions effectively. We may conclude from the above study that the converter's local control is critical to accomplishing system voltage and current regulation and establishing a coordinated control approach. Three coordinated control schemes rely on communication between dispersed components to make the DC Microgrids intelligent. Control can be decentralized, centralized, or distributed. An in-depth examination is provided above. However, DC Microgrids control will continue to expand fast in the following years to improve system efficiency and stability. This control approach will be further developed in the future.

\section{Acknowledgment}

This research was financially supported by The Faculty of Engineering, Diponegoro University, Indonesia through Strategic Research Grant 2021.

\section{References}

1. Chowdhury S and Crossley P, "Microgrids and Active Distribution Networks". IET

2. Ilhami Colak. "Voltage and Frequency Stability Analysis of AC Microgrid", IEEE, (2015)

3. Hasmaini Mohamad and Norazliani Md Sapari, "Under-Frequency Load Shedding Technique Considering Response Based for Islanding Distribution Network Connected With Mini Hydro", Int. Power Eng. Optim. Conf., (2014)

4. Rory Campbel, "Fact sheet Distributed generation", AEMC, (2012)

5. M. Sachim and S.S.K., "Costing of a Small Hydropower Projects," IACSIT Int. J. Eng. Technol., p. (2012)

6. M. Faishol Adityo, “Analisis Kestabilan Transien Pada Sistem Kelistrikan PT. Pupuk Kalimantan Timur (Pabrik KALTIM 1) Akibat Pengaktifan Kembali Pembangkit 11 MW,” Inst. Teknol.Sepuluh Nop., (2012).

7. “IEEE Recommended Practice for Monitoring Electric Power Quality." IEEE, (2009). 
8. "IEEE Guide for Abnormal Frequency Protection for Power Generating Plants." IEEE, (1987).

9. "IEEE Guide for Design, Operation, and Integration of Dis tributed Resource Island Systems with Electric Power Systems.” pp. 1-54, (2011).

10. J. J. Justo, F. Mwasilu, J. Lee, and J.-W. Jung, "AC-microgrids versus DC-microgrids with distributed energy resources: A review,” Renew. Sustain. Energy Rev., vol. 24, pp. 387-405, (2013).

11. A. T. Elsayed, A. A. Mohamed, and O. A. Mohammed, "DC microgrids and distribution systems: An overview,” Electr. Power Syst. Res., vol. 119, pp. 407-417, (2015).

12. A. Bidram and A. Davoudi, "Hierarchical Structure of Microgrids Control System," IEEE Trans. Smart Grid, vol. 3, pp. 1963-1976, (2012).

13. J. M. Guerrero, J. C. Vasquez, J. Matas, L. G. De Vicuna, and M Castilla, "Hierarchical Control of Droop Controlled AC and DC Microgrids - A General Approach Toward Standardization,” IEEE Trans. Ind. Electron., vol. 58, pp. 158-172, (2011).

14. Cook M D, Parker G G, Robinett R D, et al. Decentralized Mode-Adaptive Guidance and Control for DC Microgrid [J]. IEEE Transactions on Power Delivery, (2016):1-1.

15. Xia Y, Yu M, Tao X, et al. Decentralized control for parallel bidirectional power converters of a grid-connected DC microgrid[C]// IECON (2016) -, Conference of the IEEE Industrial Electronics Society. IEEE, 2016:6085-6090.

16. Razvan C. Rafaila, Constantin F. Caruntu, Gheorghe Livint. Centralized Model Predictive Control of Autonomous Driving Vehicles with Lyapunov Stability[J]. International Conference on System Theory, (2016), vol 13-15.

17. Morstyn T, Hredzak B, Demetriades G D, et al. Unified Distributed Control for DC Microgrid Operating Modes[J]. IEEE Transactions on Power Systems, 2015, vol 31(1):1-11.

18. Vu T V, Paran S, Diaz F, et al. An Alternative Distributed Control Architecture for Improvement in the Transient Response of DC Microgrids [J]. (2016).

19. D. J. Tylavsky and F. C. Trutt, "The Newton-Raphson Load Flow Applied to AC/DC Systems with Commutation Impedance," IEEE Trans. Ind. Appl., vol. IA-19, no. 6, pp. 940-948, Nov. (1983).

20. Li Gengyin, Zhou Ming, He Jie, Li Guangkai, and Liang Haifeng, "Power flow calculation of power systems incorporating VSC-HVDC," in 2004 International Conference on Power System Technology, (2004). PowerCon 2004., 2004, vol. 2, pp. $1562-1566$.

21. X.-P. Zhang, "Multiterminal Voltage-Sourced Converter-Based HVDC Models for Power Flow Analysis," IEEE Trans. Power Syst., vol. 19, no. 4, pp. 1877-1884, Nov. (2004).

22. C. Li, S. K. Chaudhary, J. C. Vasquez, and J. M. Guerrero, "Power flow analysis for drop controlled LV hybrid AC-DC microgrids with virtual impedance," in 2014 IEEE PES General Meeting | Conference \& Exposition, (2014), pp. 1-4.

23. T. M. Haileselassie and K. Uhlen, "Impact of DC Line Voltage Drops on Power Flow of MTDC Using Droop Control,” IEEE Trans. Power Syst., vol. 27, no. 3, pp. 1441-1449, Aug. (2012). 